Original research article

\title{
The influence of motor ability rehabilitation on temporal-spatial parameters of gait in Huntington's disease patients on the basis of a three-dimensional motion analysis system: An experimental trial
}

\author{
Elżbieta Mirek ${ }^{a}$, Magdalena Filip ${ }^{a, *}$, Wiesław Chwała ${ }^{b}$, Jadwiga Szymura ${ }^{a}$, \\ Szymon Pasiut ${ }^{a}$, Krzysztof Banaszkiewicz $^{c}$, Monika Rudzińska Bar ${ }^{d}$, \\ Andrzej Szczudlik ${ }^{e}$ \\ ${ }^{a}$ University School of Physical Education, Faculty of Motor Rehabilitation, Department of Clinical Rehabilitation and \\ Laboratory of Pathology of the Musculoskeletal System, Section of Rehabilitation in Neurology and Psychiatry, Cracow, Poland \\ ${ }^{\mathrm{b}}$ University School of Physical Education, Faculty of Physical Education and Sport, Department of Anthropomotorics, \\ Section of Biomechanics, Cracow, Poland \\ ${ }^{c}$ Department of Neurology and Neurorehabilitation, John Paul's II Hospital, Cracow, Poland \\ ${ }^{\mathrm{d}}$ Department of Neurology, Medical University of Silesia, Katowice, Poland \\ e Centrum Neurologii Klinicznej, Cracow, Poland
}

\section{A R T I C L E I N F O}

\section{Article history:}

Received 2 May 2017

Accepted 1 February 2018

Available online 12 February 2018

Keywords:

Huntington's disease

Gait

Rehabilitation

Spatio-temporal parameters

\begin{abstract}
A B S T R A C T
Objective: There is no existing standard, evidence-based, scientific model for motor ability improvement in Huntington's Disease (HD) patients aimed at maintaining independent gait for as long as possible, or performing activities of daily living, the effectiveness of which would be supported by the results of studies using objective research tools. Under these circumstances, the aim of this study was to analyze the influence of motor ability rehabilitation on the spatial-temporal parameters of gait in HD patients.

Design: It was an experimental trial. The studied group consisted of 30 patients (17 women and 13 men) with HD. In hospital conditions, the patients participated in the 3-week motor ability 1 rehabilitation programme tailored to individual needs. The study group was tested using the Vicon 250 three-dimensional gait analysis system before and after the physical exercise programme. Results: Walking speed after therapy increased for the left lower limb from 1.06 (SD 0.24) [m/ $\mathrm{s}$ ] to $1.21(\mathrm{SD} 0.23)[\mathrm{m} / \mathrm{s}]$, and for the right lower limb from 1.07 (SD 0.25$)[\mathrm{m} / \mathrm{s}]$ to 1.20 (SD 0.25) $[\mathrm{m} / \mathrm{s}]$. The cycle length increased after the applied therapy for the left lower limb from 1.17 (SD 0.20) [m] to 1.23 (SD 0.19) [m].

Conclusion: The three-week motor ability rehabilitation programme positively influences spatial-temporal gait parameters in HD patients.
\end{abstract}

() 2018 Polish Neurological Society. Published by Elsevier Sp. z o.o. All rights reserved.

\footnotetext{
* Corresponding author.

E-mail addresses: mirek.ela@wp.pl (E. Mirek), magdalena.filip@hotmail.com (M. Filip), wachwala@cyf-kr.edu.pl (W. Chwała), jagodaszymura@poczta.fm (J. Szymura), szymon.pasiut@gmail.com (S. Pasiut), k.banaszkiewicz@szpitaljp2.krakow.pl (K. Banaszkiewicz), mrudzinska@sum.edu.pl (M.R. Bar), andrzej@szczudlik.pl (A. Szczudlik).

https://doi.org/10.1016/j.pjnns.2018.02.001

0028-3843/@ 2018 Polish Neurological Society. Published by Elsevier Sp. z o.o. All rights reserved.
} 


\section{Introduction}

Huntington's disease (HD) is a neurodegenerative, progressive, incurable, hereditary disorder. Impairment of the ability to walk independently may occur in many diseases. Very often, abnormalities in gait pattern are due to diseases of the nervous system. It is believed that gait analysis is the best and only test for assessing pathologies of the nervous system [1]. The abnormalities of gait occurring in HD were qualified by Nutt as middle level gait disturbances, as a result of a pathological condition, in particular within the basal ganglia, caudate nucleus and cerebral cortex [2]. It can therefore be assumed that a person with HD should have his/her own characteristic pattern of gait disturbances, and thanks to this knowledge, it would be possible to programme an efficient motor ability improvement process. In addition, based on the available results of biomechanical studies, we can conclude that kinematic and spatialtemporal parameters of HD patients compared with healthy individuals at the same age will be different $[3,4]$. The gait of a HD patient is usually on a widened base. In the later stages of HD, patients' gait becomes stiff, cautious and reduces in speed. In addition, with the use of three-dimensional gait analysis, the researchers found the following irregularities during the gait cycle (stride): shortening the length of the gait cycle, extending the duration of the double-support phase, as well as an increase in the diversity of the duration of the gait cycle and step compared to the control group [57]. Gait instability, along with imbalances as well as psychiatric and cognition disturbances significantly contribute to falls, which occur in approximately $60 \%$ of patients with HD. The risk of falls increases with the progression of this disease [8].

An important aspect of the therapeutic process in HD, in addition to pharmacological treatment, is physiotherapy, which allows to counteract the effects of disease progression and preserve independent functioning of patients for as long as possible. This theory is confirmed by the biological basis of neurorehabilitation and the results of research on the effectiveness of physiotherapy in other diseases such as e.g. Parkinson's disease or strokes [9-11]. In 2009, The European Huntington's Disease Network's Working Group of Physiotherapy published a guide on physiotherapy in HD, including, among others, standardized assessment of the physical condition of the patients and aims of physiotherapy. In the process of gait reeducation, a physiotherapist can use the following strategies: stimulation of physical activity by teaching in the form of tasks, learning how to fall and stand up from the ground, training balancing strategies, strengthening the postural muscles [12]. There is no existing standard, evidence-based, scientific model for motor ability improvement aimed at maintaining independent gait for as long as possible, or performing activities of daily living, the effectiveness of which would be supported by the results of studies using objective research tools. Under these circumstances, the aim of this study was to analyze the influence of motor ability rehabilitation on the spatial-temporal parameters of gait in HD patients.

\section{Materials and methods}

This was an experimental trial. Patients with HD attending the Enroll HD data at the Department of Neurology, University Hospital, Jagiellonian University in Krakow were recruited. After giving their written consent, the eligible patients were clinically examined by an experienced neurologist. Inclusion criteria for the study were: HD diagnosis confirmed by genetic testing, HD motor manifestation at baseline neurological examination, stable and optima pharmacotherapy at least one month before the test and the patient's written consent to participate in the study. While the criteria for exclusion from the study included: abnormal gait preventing the subject to independently walk a distance of $20 \mathrm{~m}$ in a straight line, severe cognitive impairment MMSE $<20$ score (moderate and severe dementia), behavioural and/or psychotic disturbances preventing effective cooperation, orthopaedic disorders and the consequences of experiencing traumatic lesions to the motor organ permanently disrupting gait pattern and the presence of other chronic or acute conditions having significant impact on health, e.g. cancer, myocardial infarction, chronic pulmonary disease.

Permission to conduct research was issued by the Bioethics Committee of the Approval No.: KBET/59B/2010 and procedures were performed in accordance with the Declaration of Helsinki. Trial ID: ACTRN12617000094370.

Each patient always worked with their assigned, qualified physiotherapist, and the level of difficulty of the motor tasks was adapted to the patient's abilities. In hospital conditions, the patients participated in the 3-week motor ability rehabilitation programme, which consisted of fifteen, 90-minute individual sessions conducted daily, excluding Saturdays and Sundays.

The motor ability rehabilitation programme, whose main objective was gait re-education, was created on the basis of existing scientific reports, as well as the experience and results obtained in the evaluation of gait of patients via the Vicon system. Special attention was paid to the correct position of the pelvis, spinal curvatures, shoulder protraction, and the position of the head, knees and feet during the execution of movement by the patient. Throughout the duration of therapy, emphasis was out on proper breathing patterns, separating consecutive movement exercises by breathing exercises (e.g. blowing up a balloon, blowing soap bubbles, blowing into a tissue located at different distances from the mouth). To carry out the motor tasks, such rehabilitation equipment as handrails, mirrors, gymnastic balls, sensorimotor pillows, poles, coloured tape and weights were used. During the session, closed kinematic chains were used $70 \%$ of the time, and through the use of combining the various movement patterns, we obtained global activity of the patient's body. During the motor ability improvement, we focused on increasing the number of repetitions of a motor task, resigning from diversity of exercise. Each session consisted of three parts:

\section{Introductory part - warm-up (duration: $10 \mathrm{~min}$ )}

The aim was to raise awareness of one's own body, and to improve spatial orientation. This also included learning correct breathing patterns along with lively coordination 
exercises such as: trotting with the therapist or ball throwing.

2. Main part (duration: $70 \mathrm{~min}$ )

The aim was to mobilize functional reserves through the use of agonist/antagonist techniques, which help to learn proper gait patterns by improving coordination, endurance, balancing reactions and postural stability. This is achieved by performing certain exercises:

- exercises on a mat (position changes - turnover, the use of the following positions for motor tasks: on one's stomach supported by the forearms, lying on one's side, lateral position, backbend, sitting flat on the ground, supported kneel, one leg/both leg kneel, standing position, balancing positions, training balancing strategies)

- exercises in a seated position

- gait training (weight shifting, standing on one leg, walking forwards, backwards, sideways, defensive steps, visualspatial coordination, obstacle course, stairs)

3. Final part (duration: $10 \mathrm{~min}$ )

The objective was relaxation and tranquilization through calm breathing exercises.

Patients who met the criteria took part in the research Project including the Vicon 250 three-dimensional gait analysis system and physical exercise programme. Gait analysis using the Vicon 250 system took place in the Biokinetic Laboratory at the Department of the Biomechanics. The study group was tested just before first and just after last session of the physical exercise programme. There was no time gap before the rehabilitation process and patients' clinical rating by Vicon 250.

The Vicon 250 system allowed to record and analyze motion patterns in three-dimensional space. Registration of gait with the Vicon 250 system was performed using passive markers attached to specific anthropometric points directly on the skin, based on the Golem biomechanical model (Oxford Metrics Ltd.). During gait analysis, 30 steps performed on a 20$\mathrm{m}$ walking path were registered using five cameras operating at a frequency of $120 \mathrm{~Hz}$. The following spatial-temporal parameters for left and right leg were analyzed: stride time, stride length, step time, step length, cadence (step frequency), first double support, second double support, single limb support, heel rise (end of stance phase) and gait speed.

Normality of data (score) distribution was verified using Pearson's chi-squared test. Due to the fact that distribution of the results did not "deviate" from the normal distribution in any of the cases, parametric tests were used. The significance of differences in the average values was tested using the t-test, where statistics have Student's $t$ distribution. The level of significance was assumed at $p<0.05$. Statistical analysis of the test results was performed using Statistica 6.0 Pl Statsoft (USA).

\section{Results}

The studied group consisted of 30 patients (17 (57\%) women and 13 (43\%) men) with HD. The characteristics of the study group are presented in Table 1.

Comparison of mean values of selected spatio-temporal parameters in HD patients before and after physical therapy
Table 1 - Characteristics of the study group.

\begin{tabular}{ll} 
Variable & Study group \\
\hline Gender [female/male] & $17 / 13$ \\
Age [years] & $43.4 \pm 13.8$ \\
Disease duration [years] & $7.0 \pm 5.8$ \\
Number of CAG repetitions & $46.6 \pm 6.0$ \\
Body height [m] & $1.67 \pm 0.1$ \\
Body mass [kg] & $62.5 \pm 17.6$ \\
Walking speed [m/s] & $1.07 \pm 0.25$ \\
Cadence [Hz] & $107.6 \pm 15.6$ \\
Step length [m] & $0.59 \pm 0.11$ \\
UHDRS motor [points] & $40.8 \pm 20.0$ \\
UHDRS cognitive [points] & $123.9 \pm 43.3$ \\
TFC [points] & $7.7 \pm 3.1$ \\
\hline UHDRS - Unified Huntington's Disease rating scale. \\
TFC - total functional capacity. \\
\hline
\end{tabular}

are presented in Table 2. One of the two parameters for which a statistically significant increase was noted in the average value regarded walking speed, which increased for the left lower limb from 1.06 (SD 0.24) [m/s] to 1.21 (SD 0.23) [m/s], and for the right lower limb from 1.07 (SD 0.25) [m/s] to 1.20 (SD 0.25) [m/s]. The second parameter is cycle length, the value of which significantly increased after conducting therapy; the left lower limb from 1.17 (SD 0.20) [m] to 1.23 (SD 0.19) [m]. For the remaining analyzed variables, we observed changes aimed in the direction of the reference group values, but they were not statistically significant.

\section{Discussion}

A significant result obtained in the conducted studies is the documented impact of the created motor ability rehabilitation programme on the increase of walking speed in people with HD. The study group obtained a statistically significant improvement in the stride length only for the left side. It may result from heterogeneity in terms of severity of symptoms within the study group or asymmetry appearing in the gait pattern of HD patients. In order to explain differences between left and right stride length, the examination of a larger group is necessary. For the other analyzed spatial-temporal parameters, changes towards normative values were observed, although they were not statistically significant. The reason for this may be the insufficient duration of the motor ability rehabilitation programme. In the light of the available literature, multidisciplinary rehabilitation programmes for HD lasting 9, 18 and 24 months, respectively, resulted in significant improvement regarding motor and cognitive disorders [13,14]. Unfortunately, the time limit of our research imposing a 3-week hospitalization period was dictated by the guidelines of the National Health Fund. The advantage of the patients staying at the hospital was standardization of circadian rhythm. There was no possibility for out-patient research, since the patients came from the Malopolska, Podkarpackie and Silesia voivodeships. The use of objective measuring devices, such as Vicon system, allows to record and analyze gait changes in three-dimensional space $[12,15]$.

The literature on gait disturbances in HD, available in PubMed, Scopus and Pedro is relatively sparse. In several of 
Table 2 - Comparison of mean values for selected spatial-temporal parameters of HD patients before and after physical therapy.

\begin{tabular}{|c|c|c|c|c|c|c|c|c|}
\hline \multirow[t]{2}{*}{ The analyzed spatial-temporal parameter } & \multirow[t]{2}{*}{ Limb } & \multicolumn{2}{|c|}{ Before therapy } & \multicolumn{2}{|c|}{ After therapy } & \multirow[t]{2}{*}{$t$} & \multirow[t]{2}{*}{$\mathrm{df}$} & \multirow[t]{2}{*}{ Statistical significance $(p)$} \\
\hline & & $\bar{x}$ & SD & $\bar{x}$ & SD & & & \\
\hline \multirow[t]{2}{*}{ Stride time $[\mathrm{s}]$} & $\mathrm{L}$ & 1.15 & 0.19 & 1.10 & 0.17 & 0.96 & 58 & 0.34 \\
\hline & $\mathrm{R}$ & 1.15 & 0.21 & 1.10 & 0.21 & 0.96 & 58 & 0.34 \\
\hline \multirow[t]{2}{*}{ Stride length $[\mathrm{m}]$} & $\mathrm{L}$ & 1.17 & 0.20 & 1.23 & 0.19 & -2.54 & 58 & 0.01 \\
\hline & $\mathrm{R}$ & 1.18 & 0.21 & 1.26 & 0.18 & -1.56 & 58 & 0.13 \\
\hline \multirow[t]{2}{*}{ Step time $[\mathrm{s}]$} & $\mathrm{L}$ & 0.58 & 0.09 & 0.59 & 0.15 & -0.39 & 58 & 0.70 \\
\hline & $\mathrm{R}$ & 0.57 & 0.10 & 0.57 & 0.14 & -0.05 & 58 & 0.96 \\
\hline \multirow[t]{2}{*}{ Step length $[\mathrm{m}]$} & $\mathrm{L}$ & 0.59 & 0.10 & 0.64 & 0.10 & -1.83 & 58 & 0.07 \\
\hline & $\mathrm{R}$ & 0.59 & 0.11 & 0.63 & 0.10 & -1.51 & 58 & 0.14 \\
\hline \multirow[t]{2}{*}{ Cadence [steps/min] } & $\mathrm{L}$ & 107.63 & 15.58 & 111.76 & 15.06 & -1.03 & 58 & 0.31 \\
\hline & $\mathrm{R}$ & 107.79 & 16.56 & 111.68 & 15.80 & -0.92 & 58 & 0.36 \\
\hline \multirow[t]{2}{*}{ First double support [s] } & $\mathrm{L}$ & 0.104 & 0.05 & 0.087 & 0.04 & 1.43 & 58 & 0.16 \\
\hline & $\mathrm{R}$ & 0.108 & 0.05 & 0.101 & 0.08 & 0.38 & 58 & 0.71 \\
\hline \multirow[t]{2}{*}{ Second double support [s] } & $\mathrm{L}$ & 0.22 & 0.09 & 0.19 & 0.12 & 1.10 & 58 & 0.28 \\
\hline & $\mathrm{R}$ & 0.21 & 0.10 & 0.20 & 0.14 & 0.48 & 58 & 0.64 \\
\hline \multirow[t]{2}{*}{ Single limb support [s] } & $\mathrm{L}$ & 0.46 & 0.08 & 0.46 & 0.06 & 0.27 & 58 & 0.79 \\
\hline & $\mathrm{R}$ & 0.47 & 0.08 & 0.46 & 0.06 & 0.81 & 58 & 0.42 \\
\hline \multirow[t]{2}{*}{ Heel rise [\%] } & $\mathrm{L}$ & 58.9 & 3.49 & 57.9 & 4.46 & 1.01 & 58 & 0.32 \\
\hline & $\mathrm{R}$ & 59.5 & 3.36 & 58.6 & 3.66 & 0.99 & 58 & 0.32 \\
\hline \multirow[t]{2}{*}{ Gait speed $[\mathrm{m} / \mathrm{s}]$} & $\mathrm{L}$ & 1.06 & 0.24 & 1.21 & 0.23 & -2.46 & 58 & 0.02 \\
\hline & $\mathrm{R}$ & 1.07 & 0.25 & 1.20 & 0.25 & -2.02 & 58 & 0.04 \\
\hline
\end{tabular}

the published articles, the sample size was generally from 6 to 30 patients with symptomatic HD, representing a variety of age groups, and was always compared with a reference group comprised of 15-30 healthy age-matched participants [5-7,16-18]. Most of the works concern the evaluation of spatial-temporal parameters. So far, only 6 researchers undertook the evaluation of patients using an electronic system with passive markers used for three-dimensional motion analysis. Among the three publications, we can find analysis of changes in kinematic parameters, and only one publication analyses, according to the concept by Elftman, the relations of the "locomotor" and "passenger" during gait in people with HD [19].

The conducted review of existing literature relating to treatment available in HD still shows an insufficient number of scientific reports confirming the influence of physiotherapy on kinematic and spatial-temporal parameters of gait in people with HD [20]. The article by Busse et al. [21], based on surveys conducted among physiotherapists who work with HD patients every day, provides a good basis for the creation of standards of conduct in the physiotherapy of people with HD, and for the avoidance of basic mistakes in the course of research planning. The research conducted by Khalil et al. [22], Ulanowski [23] does not have clearly defined criteria for including/excluding patients from the study. These works relate to the wider notion of physical activity. This, however, gives reason to believe that properly conducted physiotherapy by a qualified physiotherapist and at an appropriate frequency may be included in the standards for treatment of HD patients. It should also be noted that there are several articles on comprehensive rehabilitation comprising of a plurality of elements. However, the disadvantage of this type of research is the very large number of factors affecting the physical and mental health state of patients, thus it is difficult to determine which aspect of therapy plays a key role. Much attention should also be paid to the very low intensity of the conducted interventions [24,25].

Following the review of literature, we only found one article evaluating the effectiveness of motor rehabilitation in 12 people with HD using an objective electronic gait analysis system in time and space related parameters (GAITRite system) [26]. In addition, there were still three other articles dealing with widely understood motor improvement in HD patients using subjective methods for assessing effectiveness, such as the Berg Balance Scale or the Up and Go test [21,22,24]. Bohlen et al. [26] are the only researchers so far who have examined the effect of exercise on the gait of people with HD using objective research tools. A 6-week motor ability rehabilitation programme was carried out two times a week for 1 hour in $12 \mathrm{HD}$ patients without a control group. The assessment was conducted using the GAITRite system and additionally, clinical tests. The researchers demonstrated statistically significant differences in the length of the cycle (increase), walking speed (increase) and the duration of the double support phase (reduction) following treatment. Furthermore, in clinical tests (BBS, TUG), significant improvement was not achieved after treatment [26]. Rehabilitation process seems to improve gait function less than it was described in previously published papers where not objective measurements were used. Gait and balance analysis in patients with the use of clinical tests is associated with a large margin of error resulting from the different experience of clinicians and the unreliability of human eyesight. In our study, significant improvement of spatial-temporal parameters after completion of the motor ability rehabilitation programme was achieved only in increasing the walking speed and stride length. The difference in results may be due to the significant divergence between the severity state of the movement 
disorders between the treatment groups and the duration of the motor rehabilitation programme. Capato et al., conducted a study assessing the impact of performing physical exercise with carers of HD patients which lasted 60 days (once a week for $45 \mathrm{~min}$ ). Assessment before and after completion of the exercises was performed using clinical tests (i.e. Berg Balance Scale, Up and Go Test, 6-Minute Walk Test). All 20 participants with HD forming the test group achieved statistically significant improvement concerning every single of the conducted tests [27].

The mechanisms of re-learning, improving movement quality and the acquisition of new compensatory movement patterns in diseases damaging the central nervous system are probably supported by neuronal plasticity of the undamaged brain areas. There is also scientific evidence that plasticity of the damaged central nervous system can occur as a result of the rehabilitation process. Researchers, analysing the nervous system of patients undergoing rehabilitation after a stroke, proved that thanks to movement therapy forced out of necessity, the following occurs: reorganization of the movement fields, an increase in the amplitude of evoked motor potentials, as well as changes in brain activity observed using functional magnetic resonance [28-31]. Moreover, in patients with Parkinson's disease, it has been proven in studies using functional magnetic resonance imaging that strength exercises and pharmacology also cause changes in the patterns of brain activity (the motor cortex), leading to alleviation of the symptoms [32-34]. The results of the cited experiments allow to presume that similar phenomena can occur during motor ability rehabilitation of patients with Huntington's disease.

People with HD manifest problems in physical activity as well as cognitive, emotional or social functions over an extended period of time. One of the biggest difficulties in creating comprehensive guidelines for physical therapy in such neurodegenerative diseases as HD is the great heterogeneity of clinical symptoms. This problem is not unique to HD, it relates to a general group of patients involved in neurorehabilitation, such as individuals with Parkinson's disease, those with lower lumbar pain or neck dysfunctions [35-37].

Some limitations of this study should, however, be considered. Firstly, the number of tested persons is not sufficient - the amount does not make it possible to divide the results depending on the severity of the disease, cognitive disorders, behavioural disorders or type of drug therapy. Secondly, the study group was very heterogeneous in terms of severity of symptoms. Another limitation is lack of gait assessment among the patients several weeks after the end of the motor ability rehabilitation programme.

It is debatable whether using a protocol with a control group without physiotherapy would provide any additional information. In the conducted study, it was assumed that maintaining stable drug therapy one month before the beginning of the study and during its course (taking the progressive nature of the disease into account), appropriately minimizes distortion of the image of a patient's physical state, resulting from the taken medication. The improvement of motor disorders after application of antidopaminergic drugs in HD patients is well known. In literature on the subject, there are few publications regarding the effects of drug therapy on gait in Huntington's disease. In their study, Koller et al. demonstrated that the use of haloperidol reduced the occurrence of choreic movements, but does not affect walking pattern [5]. The authors of other publications analysing isolated cases of people with HD conclude that the use of olanzapine and valproate can reduce the severity of movement and psychotic disorders [38,39]. However, conducting research among HD patients with clinical symptoms of the disease but not yet pharmacologically treated should be considered.

The three-week motor ability rehabilitation programme showed improvement regarding the majority of abnormal spatial-temporal gait parameters in patients with HD, although, statistically significant differences in gait before and after motor rehabilitation were only obtained in increasing walking speed for the lower left and right limbs, and an increase in stride length for the left lower limb. It is probable that the problems in planning and sequencing the motions may lead to deceleration in speed of the performed locomotive components, contributing to abnormal spatial-temporal gait parameters $[40,41]$.

\section{Ethics approval}

The Bioethics Committee of the Jagiellonian University in Krakow (Approval No.: KBET/59B/2010) approved this study. All participants gave written informed consent before data collection began.

Trial ID: ACTRN12617000262303

\section{Conflict of interest}

None declared.

\section{Acknowledgement and financial support}

This study was supported by University School of Physical Education grant number 264/KRK/2010.

\section{R E F E R E N C E S}

[1] Perry J, Burnfield M. Gait analysis. Normal and pathological function. 2nd ed. Slack Incorporated; 2010.

[2] Nutt G, Horak B. Classification of balance and gait disorders. In: Bronstein M, Brandt T, Woollacott $\mathrm{H}$, Nutt G, editors. Clinical disorders of balance, posture and gait. London: Arnold; 2004. p. 169-84.

[3] Knutsson E. An analysis of Parkinsonian gait. Brain 1972;95 (3):475-86.

[4] Blin O, Ferrandez M, Serratrice G. Quantitative analysis of gait in Parkinson patients increased variability of stride length. J Neurol Sci 1990;98:91-7.

[5] Koller W, Trimble J. The gait abnormality of Huntington's disease. Neurology 1985;35:1450-4.

[6] Reynolds NC, Myklebust JB, Prieto TE, Myklebust BM. Analysis of gait abnormalities in Huntington disease. Arch Phys Med Rehabil 1999;80(1):59-65. 
[7] Hausdorff JM, Cudkowicz ME, Firtion R, Wei JY, Goldberger AL. Gait variability and basalganglia disorders: stride-tostride variations of gait cycle timing in Parkinson's disease and Huntington's disease. Mov Disord 1998;13(3):428-37.

[8] Quinn L, Busse M, Broad M. Physiotherapy guidance document. Eur Huntington's Dis Netw 2009;5-26.

[9] Ward N, Newton J, Swayane O, Lee L, Thompson A, Greenwood R, et al. Motor system activation after subcortical stroke depends on corticospinal system integrity. Brain 2006;129(3):809-19.

[10] Keus S, Munneke M, Nijkrake M, Kwakkei G, Bloem BR. Physical therapy in Parkinson's disease: evolution and future challenges. Mov Disord 2009;24:1-14.

[11] Tommlinson C, Patel S, Meek C, Herd C, Clarke C, Stowe R, et al. Physiotherapy intervention in Parkinson's disease: systemic review and meta-analysis. BMJ 2012;345:e5004.

[12] Delval A, Krystkowiak P, Blatt JL, Labyt E, Bourriez JL, Dujardin $\mathrm{K}$, et al. A biomechanical study of gait initiation in Huntington's disease. Gait Posture 2007;25(February (2)):279-88.

[13] Veenhuizen R, Kootstra B, Vink W, Posthumus J, van Bekkum P, Zijlstra M, et al. Coordinated multidisciplinary care for ambulatory Huntington's disease patients. Evaluation of 18 months of implementation. Orphanet J Rare Dis 2011;6:77.

[14] Thompson J, Cruickshank TM, Penailillo L, Lee J, Newton R, Barker R, et al. The effects of a multidisciplinary rehabilitation in patients with early-to-middle stage Huntington's disease: a pilot study. Eur J Neurol 2013;20:1325-9.

[15] Barker S, Craik R, Freedman W, Herrmann N, Hilstrom H. Accuracy, reliability and validity of spatiotemporal gait analysis system. Med Eng Phys 2006;28:460-7.

[16] Rao K, Quinn L, Marder S. Reliability of spatiotemporal gait outcome measures in Huntington's disease. Mov Disord 2005;20:1033-7.

[17] Delval A, Krystkowiak P, Blatt L, Labyt E, Dujardin K, Destee A, et al. Role of hypokinesia and bradykinesia in gait disturbances in Huntington's disease: a biomechanical study. J Neurol 2006;253:73-80.

[18] Churchyard A, Morris M, Georgiou N, Chiu E, Cooper R, Iansek R. Gait dysfunction in Huntington's disease: Parkinsonism and a disorder of timing. Adv Neurol 2001;87:375-85.

[19] Chwała W, Mirek E, Rudzińska M, Frydel J, Kuźma M. The impact of involuntary movements on the spatial range of motion of the body center of mass in patients with Huntington disease. Inżynieria Biomedyczna Acta BioOptica et Informatica Medica 2013;19(2):85-94.

[20] Nance M. Therapy in Huntington's disease: where are we? Curr Neurol Neurosci Rep 2012;12(4):359-66.

[21] Busse ME, Khalil H, Quinn L, Rosser AE. Physical therapy intervention for people with Huntington's disease. Phys Ther 2008;88(7):820-31.

[22] Khalil H, Quinn L, van Deursen R, Dawes H, Playle R, Rosser A, et al. What effect does a structured home based exercise programme have on people with Huntington's disease? Clin Rehabil 2013;27(7):646-58.

[23] Ulanowski E, Danzl M. Exercise and physical therapy intervention for Huntington's disease: a case series. Mov Disord 2014;29(1):217-8.

[24] Piira A, van Walsem MR, Mikalsen G, Nilsen K, Knutsen S, Frich JC. Effects of a two-year intensive multidisciplinary rehabilitation program for patients with Huntington's disease: a prospective intervention study. Version 2. PLoS Curr 2014;(November):6 [revised 2014 Nov 25].
[25] Cruickshank TM, Thompson JA, Domínguez DJF, Reyes A, Bynevelt M, Georgiou-Karistianis N, et al. The effect of multidisciplinary rehabilitation on brain structure and cognition in Huntington's disease: an exploratory study. Brain Behav 2015;5(February (2)):e00312.

[26] Bohlen S, Ekwall C, Hellström K, Vesterlin H, Björnefur M, Wiklund L, et al. Physical therapy in Huntington's disease toward objective assessments? Eur J Neurol 2013;20(2):389-93.

[27] Capato T, Haddad M, Avila P, Tornai J, Piemonte M, Barbosa E. The mobility and functional capacity can improve in Huntington's disease patients in mid-late stages with the physical therapy and caregiver assistance. Mov Disord 2014;29(1):205.

[28] Wittenberg F, Chen R, Ishii K, Bushara O, Eckloff S, Croarkin $\mathrm{E}$, et al. Constraint-induced therapy in stroke: magneticstimulation motor maps and cerebral activation. Neurorehabil Neural Repair 2003;17(1):48-57.

[29] Koski L, Mernar TJ, Dobkin BH. Immediate and long-term changes in corticomotor output in response to rehabilitation: correlation with functional improvements in chronic stroke. Neurorehabil Neural Repair 2004;18 (4):230-49.

[30] Forrester W, Hanley F, Macko F. Effects of treadmill exercise on transcranial magnetic stimulation-induced excitability to quadriceps after stroke. Arch Phys Med Rehabil 2006;87 (2):229-34.

[31] Ro T, Noser E, Boake C, Johnson R, Gaber M, Speroni A, et al. Functional reorganization and recovery after constraintinduced movement therapy in subacute stroke: case reports. Neurocase 2006;12(1):50-60.

[32] Beall B, Lowe J, Alberts L, Frankemolle A, Thota K, Shah C, et al. The effect of forced-exercise therapy for Parkinson's disease on motor cortex functional connectivity. Brain Connect 2013;3(2):190-8.

[33] Alberts L, Linder M, Penko L, Lowe J, Phillips M. It is not about the bike, it is about the pedalling: forced exercise and Parkinson's disease. Exerc Sport Sci Rev 2011;39:177-86.

[34] Phillips D, Ridgel L, Vitek L, Koenig A, Beall B, Lowe J, et al. Comparison of motor function and cortical activation in Parkinson's disease patients following acute forcedexercise and levodopa therapy. 17th annual meeting of the international society for magnetic resonance in medicine; 2010.

[35] Kwakkel G, de Geode CJT, van Wegen EEH. Impact of physical therapy for Parkinson's disease: a critical review of literature. Parkinsonism Relat Disord 2007;13:478-87.

[36] Scheets L, Sahrmann A, Norton J. Use of movement system diagnoses in the management of patients with neuromuscular conditions: a multiple-patient case report. Phys Ther 2007;87(6):654-69.

[37] Bello-Haas D. A framework for rehabilitation of neurodegenerative diseases: planning care and maximizing quality of life. Neurol Rep 2002;26(3):115-29.

[38] Moreno L, Palau Fayos M, Díaz de Santiago A. Neuroleptic malignant syndrome induced by olanzapine in a patient with Huntington's disease. J Huntington's Dis 2012;1(1):31-2.

[39] Grove V, Quintanilla J, DeVaney G. Improvement of Huntington's disease with olanzapine and valproate. N Engl J Med 2000;28(13):973-4.

[40] Lawrence D, Weeks A, Brooks J, Andrews C, Watkins A, Harding A, et al. The relationship between striatal dopamine receptor binding and cognitive performance in Huntington's disease. Brain 1998;121:1343-55.

[41] Snowden J, Craufurd D, Grifiths H, Thompson J, Neary D. Longitudinal evaluation of cognitive disorder in Huntington's disease. J Int Neuropsysiolchol Soc 2001;7:33-44. 